\title{
Core and local skin temperature: 3-24 months old toddlers and comparison to adults
}

\author{
MDP Garcia-Souto ${ }^{1}$ and P Dabnichki ${ }^{2}$ \\ ${ }^{1}$ Medical Physics and Biomedical Engineering, University College London \\ Malet Place Engineering Building - Gower Street ,, London WC1E 6BT, UK \\ ${ }^{2}$ School of Engineering, RMIT University \\ 124 La Trobe St, Melbourne VIC 3000, Australia \\ p.garciasouto@ucl.ac.uk --- peter.dabnichki@rmit.edu.au
}

\section{Contact information:}

Dr. Pilar Garcia Souto

p.garciasouto@ucl.ac.uk

Medical Physics and Biomedical Engineering, University College London

Malet Place Engineering Building - Gower Street - London - WC1E 6BT - UK

Phone: +44 (0)20 76790454 


\begin{abstract}
The thermoregulatory responses, thermal sensation and comfort level of children are very different to those of the adult population, and should be considered in the modelling of thermal comfort and the use of climate control systems in children-shared spaces. In addition, thermoregulation is believed to be related with Sudden Infant Death Syndrome, a major cause of death in children aged below 1 year.

However experimental core and skin temperature data of the infant population is very limited, especially in toddlers. The present work investigates and reports the body core and local skin temperature characteristics of young children, as well as their dependency on gender, BMI, age, activity level and clothing. This study's novel features are:

i) clothed subjects were used and the gender representation was balanced;

ii) all subjects are children aged 3-24 months -not previously reported in the literature;

iii) it is comprehensive in terms of both infant subjects $(\mathrm{N}=138)$ and total measurements (over 9000); and

iv) it compares the characteristic body and skin temperature in adult and infant population. We observed for instance that children's core temperature is higher than for adults, while their forehead and limbs' temperature increase with age. Also, core and skin temperature seem to become more dependent on BMI with age maturation.
\end{abstract}

\title{
Keywords
}

Core Temperature; Skin Temperature; Temperature Factors; Thermoregulation Evolution; Age; Infant or toddler.

\section{List of abbreviations}

BMI: body mass index (body mass of the subject divided by the square of the height in $\mathrm{m}$ )

$\mathrm{C}$ : covered by clothing ( $\mathrm{NC}$ e not covered/exposed)

$\mathrm{H}_{\text {room: }}$ : average room relative humidity $(\%)$

Status: activity status of the infant $\{$ awake, asleep $\}$

$\mathrm{T}_{\text {room: }}$ : temperature of the room during measurement sessions

Tc: core body temperature

Ti: temperature in the points of measurement $\{i=1,2, \ldots 16, c\}$

i: index for the different body locations as indicated in Fig. 2 or Table 2. ( $\mathrm{i}=\mathrm{c}$ - indicates core body; $i=1$ - forehead, i = 2 - back of the neck, etc) 


\section{Introduction}

Thermoregulation is the ability of the body to maintain within a small range the internal temperature, predominantly aimed at maintaining constant brain temperature and only as a secondary response controlling the temperature of peripheral areas such as limbs. As the body temperature is very close to the limit of $42^{\circ} \mathrm{C}$ the main concern is core overheating. The thermoregulatory system has been a focus of research interest for more than eighty years [1]. A number of predictive models of the human thermoregulatory response to environmental conditions [2-14] are being proposed as they increase in sophistication and level of complexity. In turn this increased complexity requires substantial expansion in the experimental database that is not currently available for infants.

Thermoregulation in infants is different [15-18], both during exposure to hot $[15,17]$ and cold [17] environments; during rest [16,17] and exercise [17], evolving rapidly in the first few months after birth [19]. The evolution of the thermoregulatory system includes the emergence of circadian rhythmicity for core temperature [20], skin temperature and motor activity [21]. The difference in thermoregulation has been attributed to physical and physiological child-adult differences, i.e. morphological, locomotion-wise, cardiac output, sweating rates, etc. [17-18]. In terms of morphological differences, the higher surface area-to-mass ratio in children enhances the dry heat loss and heat absorption respectively and the smaller blood volume in infants may limit the potential for heat transfer during exposure to heat [17]. Infants also have lower tissue insulation and lower resting metabolic heat production per surface area [16]. The sweating mechanism is the main physiological difference affecting thermoregulation when exposed to heat [17], as the sweat response in infants is one third of that in adults despite them having a higher sweat gland density [16,22]. Also the onset of shivering occurs in children at a significant higher core temperature relative to the resting state [22]. These apparent thermoregulatory inferiorities that seemingly make children more vulnerable may only be relevant in extreme temperatures. However, there is a possibility that infants may exhibit alternative thermoregulatory responses at normal ambient conditions [18]. This statement is partially supported by Rowland's work [23] who found no difference in thermal balance, endurance performance or heat injury risk between children and adults undertaking exercise in the heat. 
Body temperature and skin temperature distribution are reported in several studies on adults [3,24-29]. A relatively small number of studies investigated the differences and similarities between infants and adults $[15,17,21,30-33]$ as discussed below but none addressed toddlers. Preterm newborn children of up to 13 days of age were observed to be already responsive to the operative temperatures within the incubators in the range of 28-32 ${ }^{\circ} \mathrm{C}$, with skin temperatures dependent on the location $[31,32]$. The mean skin temperature significantly decreases when infants reach 3 months while their mean activity levels increase [21]. Three months-old infants sleep for longer when exposed to lower ambient temperatures [30]. Adaptation and local disparity continues while the children grow up, presenting higher mean and local skin temperatures (forehead, abdomen, instep) than adults both at thermoneutral conditions and heat exposure [15] as well as exercise activities [17]. Similarly skin temperature is lower than in adults when exposed to cold due to greater vasoconstriction [17]. However core temperature remains the same at thermoneutral environments [17] and while at rest [15], but it is significantly higher if exposed to heat [15]. The skin temperature in children is also different in terms of temperature distribution presenting lower variations across the body ( $\mathrm{x}$ and y direction) [33].

Children have also been observed to differ in their thermal sensation, thermal comfort and temperature preference [22,34-37]. They are

- more sensitive to cold and hot environmental temperatures than adults [34,37],

- more sensitive than adults to changes in their core temperature [22], and

- have a slower rate of heat acclimation [17].

Teli et al. [34] performed a large field study where school children aged 7-11 years assessed thermal sensation and preference within naturally ventilated classrooms. The authors found that the preferred room temperatures were about $2^{\circ} \mathrm{C}$ lower than the value predicted by the adaptive comfort model used in the European Standard EN 15251, and even more significantly, they were $4^{\circ} \mathrm{C}$ lower than the values predicted by the heat balance model that uses the PMV index. The latter (PMV) was also found unsuitable for the prediction of thermal sensation in children aged 9-11 years by Ter Mors et al. [36]. Another study by Teli et al [35] showed that the thermal sensation was not dependent on the gender although male children usually preferred cooler environments than girl when subjected to high temperatures. The discrepancy between the experienced thermal 
sensation and comfort level of children in a given environment and the predictions obtained from adult-population models such as PMV clearly indicates the need to develop specific models for children to address their thermal requirements [35]. Alternatively children will continue to be subjected to classroom/kindergarten conditions that address teachers' preferences [38].

Furthermore thermoregulation is considered related with the sudden infant death syndrome (SIDS), which is the major cause of death in children up to 1 year of age, with SIDS accounting for more deaths than those from infections and allergies $[16,37]$. Skin temperature has been used in paediatric applications $[39,40]$ as well as an indicator of thermal stress; however a good understanding of skin temperature distribution in healthy subjects is required in order to achieve reliable conclusions.

However the infant skin and core temperature studies to date [15,30-33] were conducted on small number of subjects [15], that were either newborns (up to 1 month of age) $[31,32]$ or 2-14 years of age [33]. All of them were performed on naked children that is not representative to the every-day environment. Some data are historical and are no longer applicable as infants anthropometry has changed significantly in the last three decades [41]. Some utilised measuring techniques are questionable, some used thermistor probes attached to the skin with adhesive tape that effectively increases the temperature in the area [30], while others used thermal cameras at a long distance [33] without reference temperature points for the correction of errors [42]. Furthermore current thermal comfort models do not apply to children $[34,36]$. There is also a strong current interest in implementing results from thermal sensation in climatic control using artificial intelligence [43], climatic control in shared spaces [44,45], influence of environment on sleep comfort [46] and thermal sensation in moderate activities [47]. In conclusion, the need for more research focused on children is recognized in the literature with suggestions of research on children thermal requirements in current and future climates [35]. The first necessary step is to investigate the differences in temperature distribution between children and adults in various regions, most sensitive index of temperature exposure, and sensitive impact of extreme temperatures [37].

The motivation for the current work was to improve the understanding of core body temperature and skin temperature distribution in young children aged 3-24 months. This 
is a particularly important group as they are not able to inform their carers of how they feel. The focus of the reported results is on clothed children at normal indoor climate conditions, i.e. mild room temperatures of 23.7 (SD 1.7) ${ }^{\circ} \mathrm{C}$, no strong radiation temperature and $55.1(\mathrm{SD}=6.8) \%$ humidity.

The aims of this study were to

i) obtain a map of the body temperature distribution based on a large number of samples among infants between 3 and 24 months of age,

ii) identify factors affecting the core temperature and local skin temperature distribution at selected locations based on the existing ISO standards 9886 [48], and

iii) compare the core temperature and local skin temperature of children with that of adults at similar environmental conditions.

\section{Method}

\subsection{Scope}

Two populations were investigated in this paper: (a) children between 3 and 24 months of age; (b) adults.

The children cohort was recruited and tested following a study protocol approved by the University of London Ethical Committee (QMREC2008/72). Permission to perform the data collection at their premises was obtained from all participating nurseries, followed by informing and obtaining consent from the parents. The researcher was then embedded in each nursery so children got accustomed and collaborated. Those who were not willing were not measured. All measurements were taken in nurseries during their opening hours (9am to 6pm) while infants performed normal daily activities. Four London based and two Spanish nurseries participated in the study. A total of 138 subjects participated in the study. Core temperature and 16 local skin temperatures were measured in 540 occasions, deeming a total of 9180 samples. Volunteers' gender, age, Body Mass Index (BMI) and clothing were recorded. Subjects were classified as awake or asleep as young children do not have otherwise a great difference in the metabolic rate. 
The group stratification in terms of gender, age, BMI and status is given in Figure 1(ac). The constitution of the children was assessed through BMI as used by the World Health Organization (WHO) since the early 1980s [49]. There are no standard ranges for underweight, normal or overweight for very young children [50]. Therefore for the purpose of this study three different categories were notionally defined with cuts based on the percentiles 20 and 80 of the BMI distribution for the study sample, i.e. 16.53 and $19.25 \mathrm{~kg} / \mathrm{m}^{2}$. Those categories were tagged as light, normal or heavy.

The adult cohort sample presented in this paper was selected from a larger experimental database collected and previously reported by the authors [24] and power matched with infants' samples. This set corresponds to 38 adults between 21 to 64 years, with BMI of 18.5 to $31.1 \mathrm{~kg} / \mathrm{m}^{2}$, both genders equally represented (18 female, 20 male), all performing sedentary activities while remaining seated. Core temperature (left and right ear), forehead temperature and other 6 local skin temperatures (both at the left and right side of the body) were measured in 167 occasions, deeming a total of 2505 samples. Volunteer's gender, age, BMI and clothing were recorded. The group stratification is given in Figure 1(d-e).

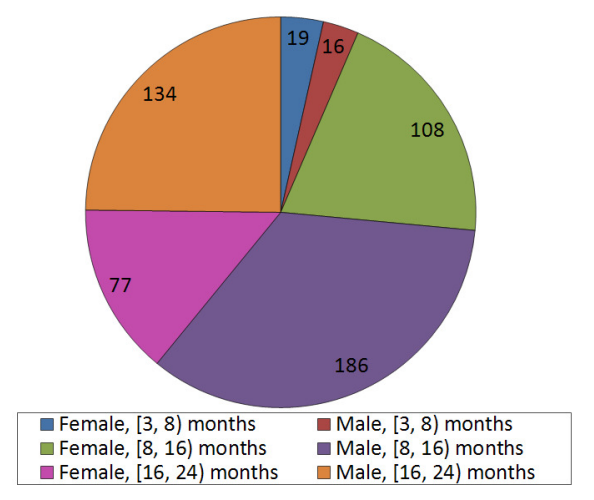

(a)

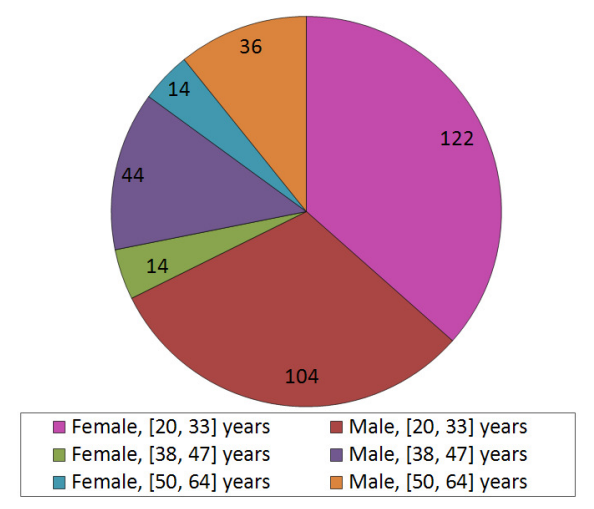

(d)

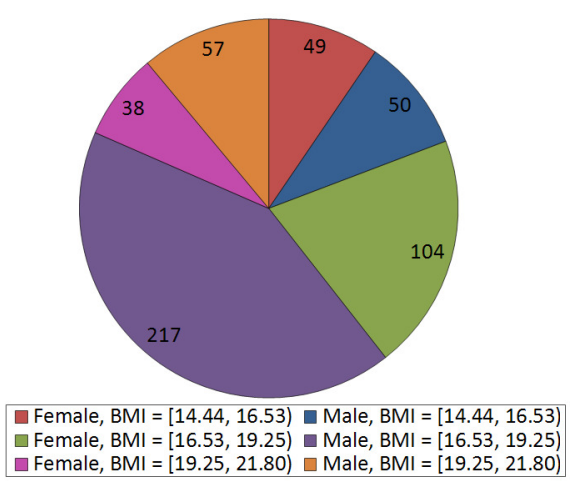

(b)

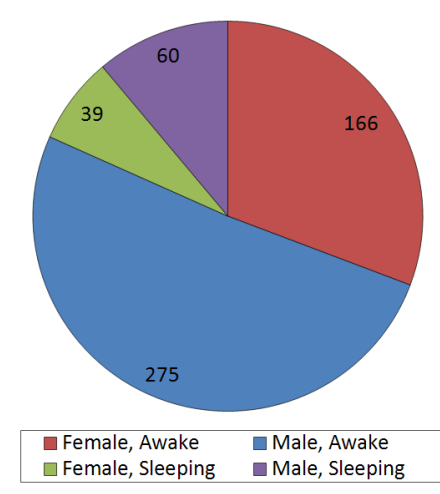

(c)

Figure 1. Group stratification. (a-c) Infant cohort; (d-e) Adult cohort. 


\subsection{Experimental procedure}

Children's core and skin temperature at 16 locations was obtained at least three times during their stay at the nursery. Skin temperature at exposed locations was measured first, followed by temperature underneath clothed areas. Core temperature was taken last. In order to reduce the error, core temperature was measured twice each time while skin temperature was measured three times and averaged. Intra-variation and intervariation were small, about the accuracy of the measurement device, $0.2^{\circ} \mathrm{C}$, and so attributed to the accuracy of the measurement. Children's gender, age, BMI, status (awake vs. asleep) and clothing were recorded. Clothing was observed in terms of number of layers at each point of measurement. As in nearly all cases layers were cotton, this is a practical way to determine the individual isolation levels [51]. The tog rating for the blankets used during this experiment was 2.5 .

The skin temperature locations were the 14-points in ISO 9886 [48] plus two additional points (lateral of the neck, T15, and left wrist, T16) as they are visible, hence convenient for placing monitoring sensors (see Figure 2).

Measurements were taken only after subjects adapted to the environment to ensure comparability [52]. A minimum of 15 minutes stay in the room was observed as such duration is sufficient to reach stable skin temperature level [53]. Three to seven measurements were taken for each volunteer in a given day allowing a minimum of one hour between them. These measurements were timed to cover different days and times of the day with the associated variation on environmental temperature and humidity, and various personal conditions such as level of activity and clothing.

All measurements were taken indoors at the nurseries. Room temperature and humidity at the nurseries could not be modified for this study but was maintained within a narrow range $\left(23.7^{\circ} \mathrm{C}\left(\mathrm{SD}=1.7^{\circ} \mathrm{C}\right)\right.$ and $\left.55.1 \%(\mathrm{SD}=6.8 \%)\right)$. There was no significant air velocity as drafts affecting the volunteers, both from doors or air conditioning systems, were avoided. Radiant temperature from direct exposure to the sun or/and heating elements was negligible as data collection rooms had either no windows or they were covered with blinds/full window size stickers; and the designated area for the children 
had no heating elements to avoid accidents. As a result wind chill and radiant temperature were insignificant and therefore not considered.

The sample data for adults presented in this paper was selected as to match the environmental conditions to which the infants were subjected $\left(23.80{ }^{\circ} \mathrm{C}\right.$ with $\mathrm{SD}=0.90$ ${ }^{\circ} \mathrm{C}$ and $42.7 \%$ humidity with $\mathrm{SD}=11.2 \%$ ). The experimental procedure and equipment were identical to those used in infants as to allow for comparisons between the two groups (adults and infants). Full description of the experimental procedure for the adult cohort can be seen in the previous paper [24]. Note that the tags used for each location have been adapted as to match those used in Figure 2. Only frontal locations were investigated as adults remained seated.

\subsection{Equipment}

Meteorological stations were used to monitor temperature and humidity in the data collection room. The minimum room size was $3.0 \mathrm{~m}$ x $4.8 \mathrm{~m}$ and $3.0 \mathrm{~m}$ height. The units were positioned by the wall in opposite sides of the room at the children's head level (heights between 40 to $70 \mathrm{~cm}$ ) to obtain the average temperature $\left(T_{\text {room }}\right)$ and relative humidity $\left(\mathrm{H}_{\mathrm{room}}\right)$ that they were experiencing.

Tympanic temperature, used as core temperature in this study, was measured using infrared sensor (OMRON Healthcare Co., Ltd., model MC-510-E2, accuracy of $0.1^{\circ} \mathrm{C}$ ). The sensor is specially designed for babies as it has a smaller head. It provides consistent measurements of the tympanic temperature by recording the maximum value in 10 seconds as established in clinical practice (the tympanic temperature is higher than the rest of the inner ear temperature). Furthermore, in order to improve the accuracy of the obtained value, 2 consecutive measurements were taken and averaged.

Infrared sensor (Medscope Ltd., model TH03F, accuracy $0.2^{\circ} \mathrm{C}$ ) was used to measure the skin temperatures. Three consecutive measurements for each skin and clothing location were taken and averaged in order to improve the accuracy of the obtained values. Both sensors (OMRON and Medscope) are approved and commonly used in the UK's National Health System (NHS). 


\subsection{Data Analysis}

\subsubsection{Core and skin temperature distribution in infants and identification of relevant}

factors

Mean and standard deviation are given as representation of most likely core and skin temperature values in toddlers. The normality of each temperature distribution was assessed on the whole data set and sub-cohorts defined by the studied parameters (gender, age, BMI, clothing when applicable, status-awake vs. asleep and use of a 2.5tog-blanket while sleeping), i.e. 13 cohorts at 17 locations -core and 16 local skin temperatures- giving a total of 231 distributions. A maximum absolute deviation of 2 from normality both for Skewness and Kurtosis was applied as criteria.

The relevance of each parameter (i.e. gender, age, BMI, clothing, status, use of blanket while sleeping) was then tested separately at each location (a total of 90 cases). The complete data set was split into sub-cohorts based on each of the studied parameters and if their distributions were statistically different the factor was deemed relevant. The statistical test used in each case was carefully chosen:

- Standard ANOVA test (named test 1A): if the whole dataset and each sub-cohort distributions are normal and the variances equivalent (assessed with the Levene test);

- Welch and Brown-Forsythe tests, a robust test of equality of means (named test $1 B)$ : if the whole dataset and each sub-cohort distributions are normal but the variances are not equivalent (assessed with the Levene test);

- Non-parametric tests, i.e. Mann-Whitney U test (compare only 2 cohorts) (named test 2) and Kruskal-Wallis 1-way ANOVA (3+ cohorts) (named test 3): used when normal distributions were not guaranteed, as these tests do not assume normality or equal variances among the cohorts.

\subsubsection{Factors for core and skin temperature distribution in adults}

Body and local skin temperature observed in adults was similarly studied for the identification of relevant factors following the procedure described in section 2.4.1. The studied parameters were gender, age, BMI and clothing. 


\subsubsection{Comparison of core and skin temperature for adults and infants}

The characteristic body and local skin temperature for adults and infants were compared, both in terms of mean values and statistically relevant factors affecting the temperature distribution at each location. The adult cohort was obtained using random sampling, and extracted from a much larger cohort as described in [24] and represents the active segment normally in employment. The children were separated in cohorts representing the normal nursery/kindergarten grouping, i.e. stratified sampling. The samples were power matched. The cohorts were matched, i.e. only awake volunteers subjected to similar room temperature $\left(23.80(\mathrm{SD}=0.90){ }^{\circ} \mathrm{C}\right.$ for adults and $23.7(\mathrm{SD}=$ 1.7) ${ }^{\circ} \mathrm{C}$ for infants).

The effect of maturation among infants was further studied by observing the change on the body and local skin temperature with age and comparing with those of adults as control. The sub-cohorts for age used were those defined for each population (section 2.1). Normality of the distributions was studied for this sample and the statistical significant difference between consecutive cohorts by age identified and presented, helping to establish when age becomes relevant within a wide span of values.

\subsubsection{Comparison of core and skin temperature distribution for infants with other studies}

The estimated values or core and local skin temperatures as well as the identified factors affecting them in infants were compared with those reported in the literature. The studies detailed in Table 1 were used as they provide experimental data on local skin temperature of children. The comparison is challenging as age range of the infants varies widely as well as the experimental protocol. However these studies were used as no other published experimental data were found, especially for the studied age range (3-24 months). 


\begin{tabular}{|c|c|c|c|c|c|}
\hline Source & $\begin{array}{l}\text { Sample } \\
\text { size }\end{array}$ & Age & Troom & $\begin{array}{l}\text { Measuring } \\
\text { technique }\end{array}$ & Other specifics \\
\hline $\begin{array}{l}\text { Present } \\
\text { work }\end{array}$ & $\begin{array}{l}138 \\
\text { subjects }\end{array}$ & $\begin{array}{l}3-24 \\
\text { months }\end{array}$ & $\begin{array}{l}23.7 \\
(1.7)^{\circ} \mathrm{C}\end{array}$ & IR thermometer & $\begin{array}{c}\text { Clothed. } \\
\text { Male vs. female. } \\
\text { Awake vs. } \\
\text { asleep. } \\
\text { Age. BMI. }\end{array}$ \\
\hline $\begin{array}{l}\text { [Tourula, } \\
\text { 2010] }\end{array}$ & 33 & $\begin{array}{l}3 \\
\text { months }\end{array}$ & $\begin{array}{l}22.1 \\
(1.5)^{\circ} \mathrm{C}\end{array}$ & $\begin{array}{l}\text { Taped } \\
\text { thermistor } \\
\text { probes }\end{array}$ & $\begin{array}{l}\text { Sleeping } \\
\text { indoors. } \\
\text { Clothed. }\end{array}$ \\
\hline $\begin{array}{l}\text { [Kolosovas- } \\
\text { Machuca, } \\
\text { 2011] }\end{array}$ & 25 & $\begin{array}{l}2-14 \\
\text { years }\end{array}$ & $\begin{array}{l}22 \pm \\
1^{\circ} \mathrm{C}\end{array}$ & $\begin{array}{l}\text { IR thermography } \\
\text { at } 1.5 \mathrm{~m} \text { distance }\end{array}$ & $\begin{array}{c}\text { Average and } \\
\text { male vs. female. } \\
\text { Naked }\end{array}$ \\
\hline $\begin{array}{l}\text { [Clark, } \\
\text { 1980] }\end{array}$ & $\begin{array}{l}7 \& \\
12\end{array}$ & $\begin{array}{l}5-11 \\
\text { days }\end{array}$ & $\begin{array}{l}32^{\circ} \mathrm{C} \\
28^{\circ} \mathrm{C}\end{array}$ & $\begin{array}{l}\text { IR thermography } \\
\text { while in } \\
\text { incubator. }\end{array}$ & $\begin{array}{c}\text { 'Calculated' } \\
\text { values. } \\
\text { Naked. } \\
\end{array}$ \\
\hline $\begin{array}{l}\text { [Karlson, } \\
\text { 1995] }\end{array}$ & 25 & $\begin{array}{l}2-9 \\
\text { days }\end{array}$ & $\begin{array}{l}28.6^{\circ} \mathrm{C} \\
32.1^{\circ} \mathrm{C}\end{array}$ & $\begin{array}{l}\text { Contact skin } \\
\text { thermometer } \\
\text { while in } \\
\text { incubator. }\end{array}$ & Naked. \\
\hline
\end{tabular}

Table 1: Existing skin temperature studies in children that are used here for comparison.

\section{Results}

\subsection{Expected values of core and local skin temperatures of infants}

The core temperature distribution for the infants' cohort was characterized. The expected core temperature is $36.59 \pm 0.02{ }^{\circ} \mathrm{C}$, with a small standard deviation of 0.40 ${ }^{\circ} \mathrm{C}$, and the distribution is normal (Kurtosis $=0.84$ and Skewness $=0.14$ ).

Equivalent analysis was performed for the skin temperature at each of the 16 proposed locations. The expected temperatures are presented in table $\mathbf{2}$ and illustrated in Figure 2. When considering the entire dataset, most locations had a normal or nearly normal temperature distribution. Minor deviations were found at $T 14$ (right instep) which is not perfectly symmetric. Scarcely populated right wing is presented in most of the locations but $T 1, T 2$ and $T 6$. Only temperature distributions at the neck ( $T 2$ and $T 15$ ) were found to be non-normal due to high Kurtosis, i.e. they are more pointed than normal distribution. 


\begin{tabular}{|c|c|c|c|c|}
\hline \multicolumn{5}{|c|}{ Expected Core and Local Skin Temperatures in Infants } \\
\hline & Location & $\mathbf{N}$ & Mean $\left({ }^{\circ} \mathrm{C}\right)$ & $\mathrm{SD}\left({ }^{\circ} \mathrm{C}\right)$ \\
\hline Tc & Core & 540 & 36.59 & 0.40 \\
\hline T1 & Forehead & 539 & 33.80 & 0.75 \\
\hline $\mathbf{T 2}$ & Back of neck & 538 & 34.53 & 0.90 \\
\hline T3 & Right scapula & 537 & 34.59 & 0.84 \\
\hline $\mathbf{T 4}$ & Left upper chest & 531 & 34.0 & 1.0 \\
\hline T5-C & Right upper arm - covered & 445 & 32.8 & 1.0 \\
\hline T5 - NC & Right upper arm - exposed & 13 & 31.1 & 1.3 \\
\hline T6 - C & Left lower arm - covered & 160 & 31.2 & 1.3 \\
\hline T6 - NC & Left lower arm - exposed & 295 & 30.8 & 1.4 \\
\hline T7 & Left hand & 537 & 32.0 & 1.8 \\
\hline T8 & Right side of abdomen & 530 & 34.50 & 0.93 \\
\hline T9 & Left paravertebral & 528 & 33.9 & 1.0 \\
\hline T10 & Right anterior thigh & 531 & 31.8 & 1.4 \\
\hline T11 & Left posterior thigh & 531 & 32.6 & 1.2 \\
\hline T12-C & Right shin - covered & 322 & 31.7 & 1.4 \\
\hline T12-NC & Right shin - exposed & 137 & 31.5 & 1.5 \\
\hline T13 - C & Left calf - covered & 321 & 31.2 & 1.5 \\
\hline T13 - NC & Left calf - exposed & 137 & 31.3 & 1.4 \\
\hline T14 - C & Right instep - covered & 287 & 33.1 & 1.7 \\
\hline T14 - NC & Right instep - exposed & 154 & 32.4 & 2.0 \\
\hline T15 & Neck in lateral location & 425 & 35.15 & 0.77 \\
\hline T16 & Left wrist & 432 & 31.1 & 1.5 \\
\hline
\end{tabular}

Table 2: Local mean and standard deviation of skin temperature distributions in infants. SD given with 2 s.f. 


\section{Expected skin temperatures in clothed babies}

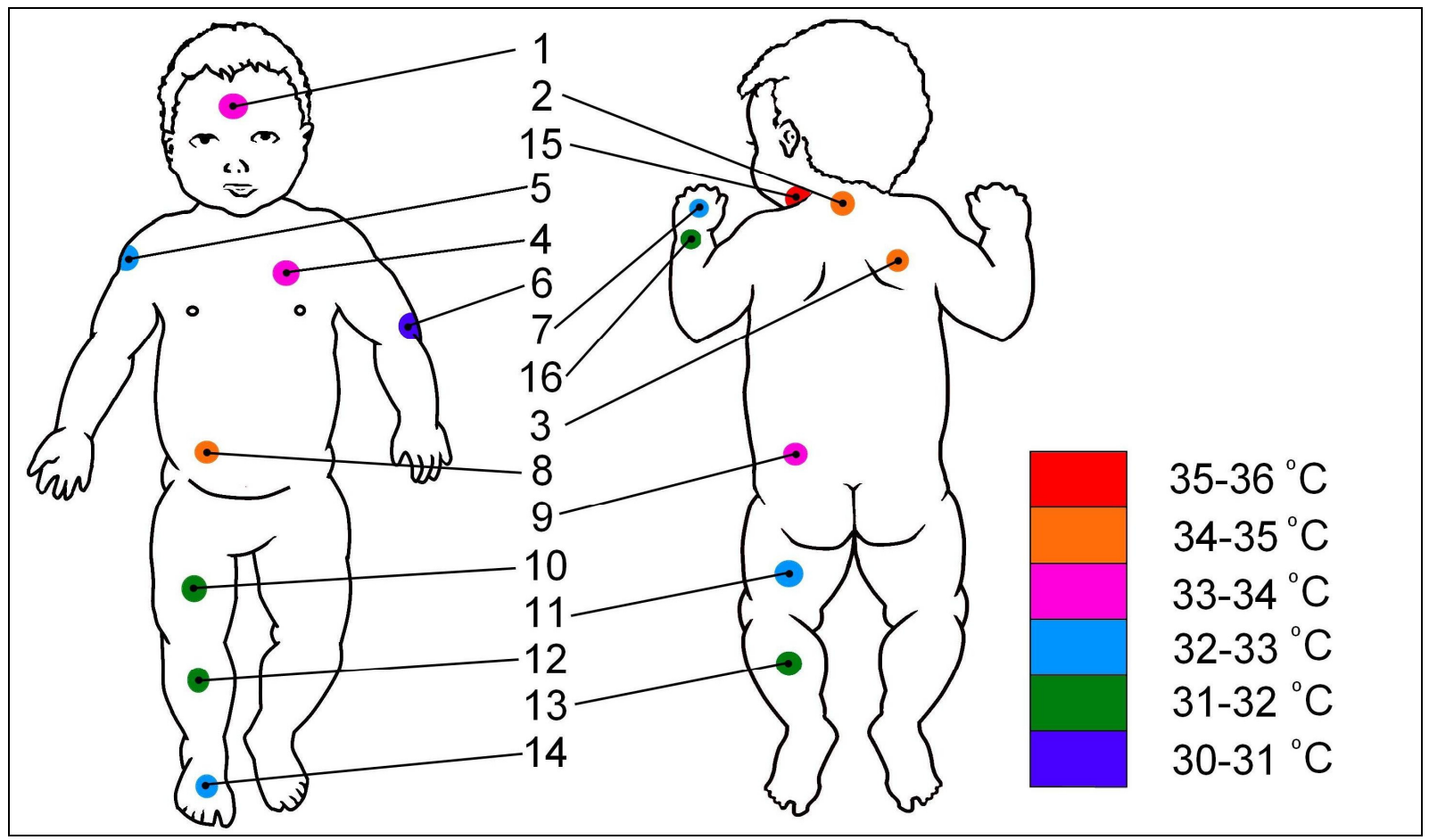

Figure 2: Expected local skin temperatures in clothed infants when whole dataset is considered

\subsection{Factors influencing core and local skin temperatures in infants}

The following potential factors of infant core temperature and local skin temperature were investigated: gender, age, BMI, clothing, status (awake vs. asleep) and use-ofblanket while sleeping. The different categories are described in Figure 1(a-c). Statistical tests used and parameters found relevant are provided in Table 3.

Gender, status and the use-of-blanket-while-sleeping were found relevant for infant core temperature, while age and BMI were identified as non-relevant. Infant core temperature was on average higher for female than for male babies by $0.12 \pm 0.04^{\circ} \mathrm{C}$, higher for awake babies by $0.33 \pm 0.04^{\circ} \mathrm{C}$, and lower for babies sleeping with blanket than those without blanket by $0.17 \pm 0.08^{\circ} \mathrm{C}$.

All local skin temperature values seem to be dependent on the status of the infant. Age and BMI seem relevant to most locations, while gender only affects the skin temperature at hands. Clothing also significantly affects the skin temperature in most cases, either local clothing or blanket. The increase of temperature at T5, T6 and T14 
with the local clothing classified as the number of layers covering the skin is given in Figure 3.

\begin{tabular}{|c|c|c|c|c|c|c|}
\hline Location & Gender & Age & BMI & Status & Blanket & Clothing \\
\hline Tc & $1 \mathrm{~A}$ & $1 \mathrm{~B}$ & 3 & 2 & 2 & --- \\
\hline T1 & $1 \mathrm{~A}$ & $1 \mathrm{~A}$ & $1 \mathrm{~A}$ & $1 \mathrm{~A}$ & $1 \mathrm{~A}$ & --- \\
\hline T2 & 2 & 3 & 3 & 2 & 2 & --- \\
\hline T3 & $1 \mathrm{~A}$ & $1 \mathrm{~A}$ & $1 \mathrm{~A}$ & $1 \mathrm{~A}$ & 2 & --- \\
\hline T4 & $1 \mathrm{~A}$ & $1 \mathrm{~A}$ & $1 \mathrm{~A}$ & $1 \mathrm{~A}$ & 2 & --- \\
\hline T5 & $1 \mathrm{~A}$ & 1B & 1B & $1 \mathrm{~A}$ & $1 \mathrm{~A}$ & $1 \mathrm{~A}$ \\
\hline T6 & $1 \mathrm{~A}$ & 1B & $1 \mathrm{~A}$ & 1B & 1B & $1 \mathrm{~A}$ \\
\hline T7 & 1B & $1 \mathrm{~A}$ & $1 \mathrm{~A}$ & 1B & 1B & --- \\
\hline T8 & $1 \mathrm{~A}$ & $1 \mathrm{~A}$ & $1 \mathrm{~A}$ & $1 \mathrm{~A}$ & 1B & --- \\
\hline T9 & $1 \mathrm{~A}$ & $1 \mathrm{~A}$ & $1 \mathrm{~A}$ & 1B & 2 & --- \\
\hline T10 & $1 \mathrm{~A}$ & 1B & $1 \mathrm{~A}$ & 1B & $1 \mathrm{~A}$ & --- \\
\hline T11 & $1 \mathrm{~A}$ & $1 \mathrm{~A}$ & $1 \mathrm{~A}$ & $1 \mathrm{~A}$ & $1 \mathrm{~A}$ & --- \\
\hline T12 & $1 \mathrm{~A}$ & $1 \mathrm{~A}$ & $1 \mathrm{~A}$ & 1B & $1 \mathrm{~A}$ & $1 \mathrm{~A}$ \\
\hline T13 & $1 \mathrm{~A}$ & $1 \mathrm{~A}$ & $1 \mathrm{~A}$ & $1 \mathrm{~A}$ & $1 \mathrm{~A}$ & $1 \mathrm{~A}$ \\
\hline T14 & $1 \mathrm{~A}$ & 1B & $1 \mathrm{~A}$ & 1B & 1B & 1B \\
\hline T15 & 2 & 3 & 3 & 2 & $1 \mathrm{~A}$ & --- \\
\hline T16 & $1 \mathrm{~B}$ & 1B & $1 \mathrm{~A}$ & $1 \mathrm{~A}$ & 1B & --- \\
\hline
\end{tabular}

Table 3: Summary of statistical tests used for the identification of factors influencing core and local skin temperature of infants and results. (1A) ANOVA with homogeneous variance, (1B) ANOVA with different variances, (2) Mann-Whitney $U$ test, and (3) Kruskal-Wallis. (Black) Distributions are equivalent, and (Bold red) Distributions are different hence the parameter is relevant.

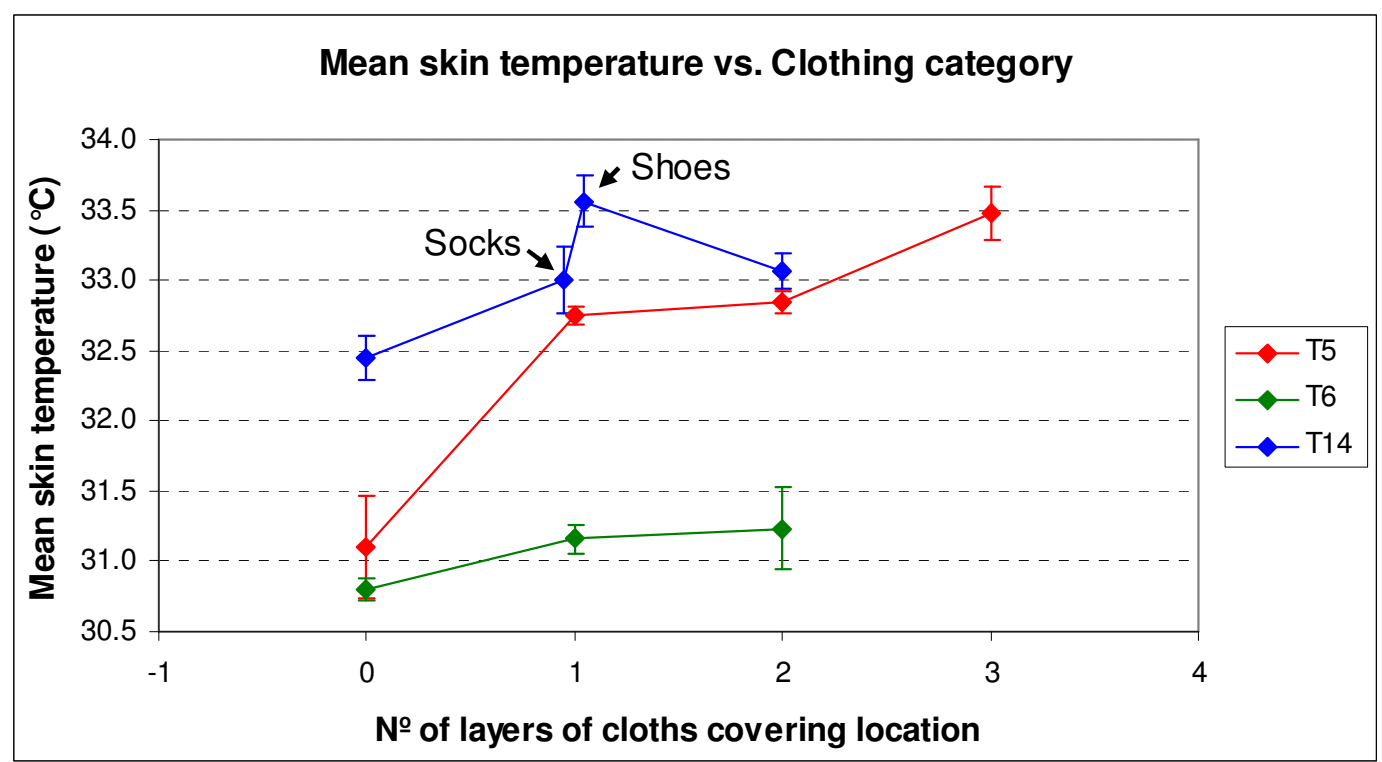

Figure 3: Mean skin temperature at upper arm (T5), lower arm (T6), and instep (T14) locations versus number of layers covering the location. For the instep (T14), two cases of only one layer were considered, socks and shoes. 


\subsection{Factors influencing core and local skin temperature of adults}

The following potential factors of adult core temperature and local skin temperature were investigated: gender, age, BMI, and clothing. The different categories are described in Figure 1(d-e). Statistical tests used in each case and parameters found relevant are provided in Table 4.

\begin{tabular}{ccccc}
\hline Location & Gender & Age & BMI & Clothing \\
\hline Tc & 1B & 1B & 1B & --- \\
\hline T1 & 2 & 3 & 2 & --- \\
\hline T4 & 2 & 3 & 2 & --- \\
\hline T5-covered & $1 \mathrm{~A}$ & $1 \mathrm{~B}$ & 2 & 2 \\
\hline T7 & 2 & $1 \mathrm{~B}$ & $1 \mathrm{~B}$ & --- \\
\hline T8 & $1 \mathrm{~B}$ & 1B & 2 & --- \\
\hline T12-covered & 2 & $1 \mathrm{~A}$ & 2 & $1 \mathrm{~B}$ \\
\hline T knees & $1 \mathrm{~B}$ & 1B & $1 \mathrm{~A}$ & $1 \mathrm{~A}$
\end{tabular}

Table 4: Summary of statistical tests used for the identification of factors influencing core and local skin temperature distribution of adults and results. (1A) ANOVA with homogeneous variance, (1B) ANOVA with different variances, (2) Mann-Whitney $U$ test, and (3) Kruskal-Wallis. (Black) Distributions are equivalent, and (Bold red) Distributions are different hence the parameter is relevant.

\subsection{Core and skin temperature: comparison between awake infant and adult population}

The core and local skin temperature for awake infants and adults were compared in terms of their distributions (Table 5) and their relevant factors (Table 6). The effect of maturation was studied more in detail by observing the change on the body and local skin temperature with age (Figure 4). Consecutive cohorts presenting no significant temperature difference at 0.05 level were indicated in the graphs by a linking bracket. Results for upper arm and shin locations were only reported specifically when covered with clothing, as samples taken while the areas were exposed were predominantly associated with female volunteers, hence gender unbalanced. 


\begin{tabular}{lllllll}
\hline & \multicolumn{3}{c}{ Babies } & \multicolumn{3}{c}{ Adults } \\
\cline { 2 - 7 } & $\mathbf{N}$ & Mean & SD & $\mathbf{N}$ & Mean & SD \\
\hline Body core & 441 & 36.65 & 0.38 & 334 & 36.27 & 0.37 \\
\hline Forehead & 440 & 33.90 & 0.70 & 167 & 34.1 & 0.82 \\
\hline Upper chest & 439 & 33.85 & 0.98 & 332 & 34.2 & 1.0 \\
\hline Upper arm - covered & 429 & 32.90 & 0.99 & 252 & 33.34 & 0.93 \\
\hline Abdomen & 435 & 34.42 & 0.93 & 318 & 33.4 & 1.4 \\
\hline Hands & 438 & 31.8 & 1.8 & 334 & 32.6 & 1.4 \\
\hline Shin - covered & 334 & 31.6 & 1.3 & 297 & 32.2 & 1.0 \\
\hline Shin - exposed & 104 & 31.2 & 1.4 & 36 & 31.11 & 0.63 \\
\hline Table 5: Mean skin tempery
\end{tabular}

Table 5: Mean skin temperature $\left({ }^{\circ} \mathrm{C}\right)$ at similar room temperatures for two different populations, awake adults and awake babies. SD given with 2 s.f..

\begin{tabular}{|c|c|c|c|c|c|c|c|c|}
\hline & $\begin{array}{l}\text { Gender } \\
\text { infants }\end{array}$ & $\begin{array}{l}\text { Gender } \\
\text { adults }\end{array}$ & $\begin{array}{l}\text { Age } \\
\text { infants }\end{array}$ & $\begin{array}{l}\text { Age } \\
\text { adults }\end{array}$ & $\begin{array}{l}\text { BMI } \\
\text { infants }\end{array}$ & $\begin{array}{l}\text { BMI } \\
\text { adults }\end{array}$ & $\begin{array}{l}\text { Cloth } \\
\text { infants }\end{array}$ & $\begin{array}{l}\text { Cloth } \\
\text { adults }\end{array}$ \\
\hline Body core & $\sqrt{ }$ & $\sqrt{ }$ & 0 & $\sqrt{ }$ & $\mathbf{0}$ & $\sqrt{ }$ & - & - \\
\hline Forehead & 0 & 0 & $\sqrt{ }$ & $\mathbf{0}$ & $\sqrt{ }$ & $\sqrt{ }$ & - & - \\
\hline $\begin{array}{l}\text { Upper } \\
\text { chest }\end{array}$ & 0 & 0 & 0 & $\sqrt{ }$ & $\sqrt{ }$ & $\sqrt{ }$ & - & - \\
\hline $\begin{array}{l}\text { Upper arm } \\
\text { - covered }\end{array}$ & o & $\mathbf{0}$ & $\sqrt{ }$ & $\mathbf{0}$ & $\mathrm{O}$ & $\sqrt{ }$ & $\sqrt{ }$ & $\sqrt{ }$ \\
\hline Abdomen & 0 & 0 & 0 & $\sqrt{ }$ & $\sqrt{ }$ & $\sqrt{ }$ & - & - \\
\hline Hands & $\sqrt{ }$ & $\sqrt{ }$ & $\sqrt{ }$ & $\sqrt{ }$ & 0 & $\sqrt{ }$ & - & - \\
\hline $\begin{array}{l}\text { Shin - } \\
\text { covered }\end{array}$ & 0 & 0 & $\sqrt{ }$ & $\sqrt{ }$ & $\mathbf{0}$ & $\sqrt{ }$ & $\sqrt{ }$ & $\sqrt{ }$ \\
\hline
\end{tabular}

Table 6: Body temperature relevant factors for two different populations, awake infants and awake adults: $(0)$ indicates no relevance; $(\sqrt{ })$ indicates relevance at 0.05 level. 

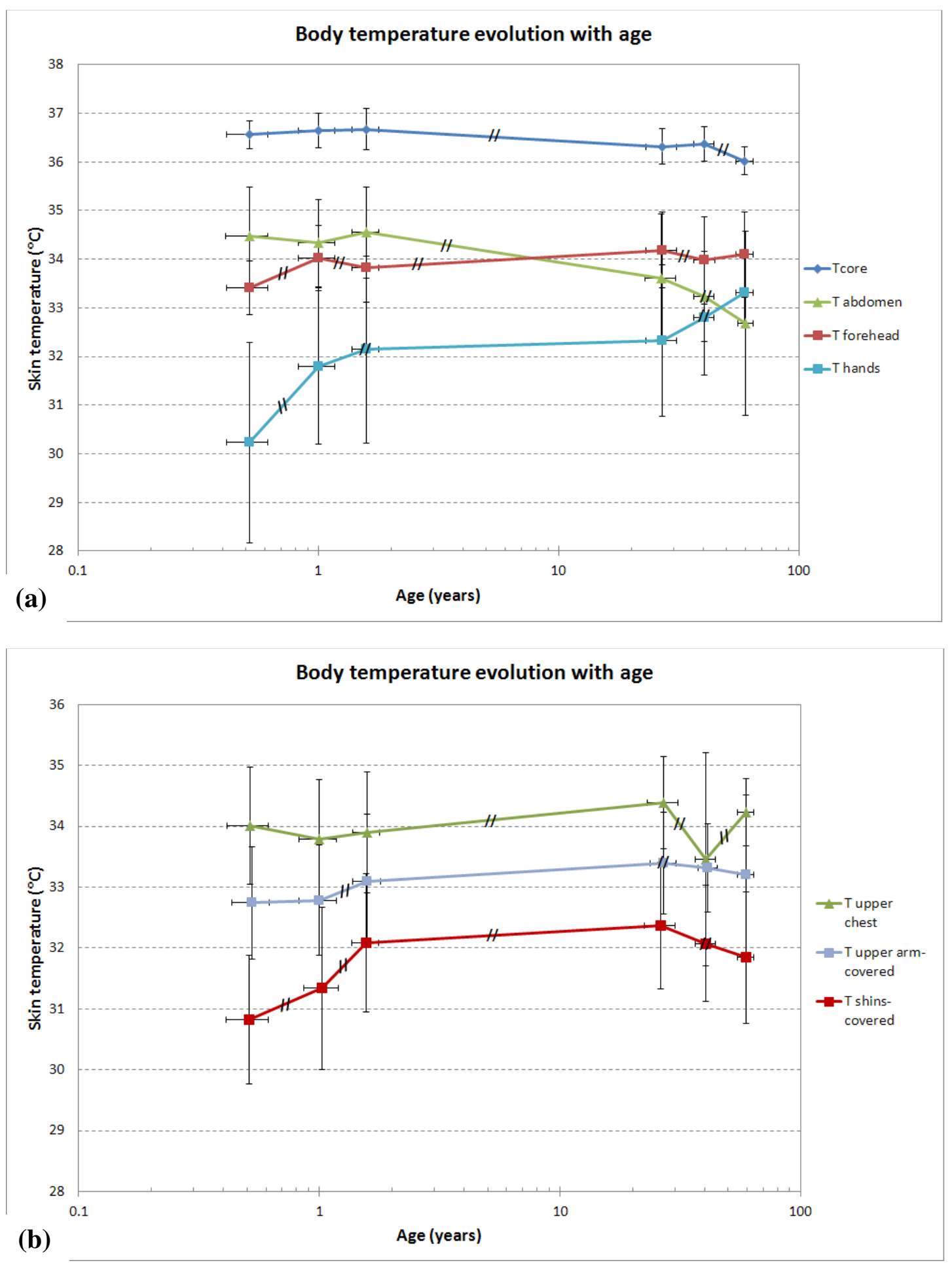

Figure 4 (a-b): Core and local skin temperature versus age from early childhood to adulthood. Data corresponds only to awake volunteers. Consecutive cohorts presenting significant difference at 0.05 level were indicated by ' $/$ '. When located over the data point for a cohort, this symbol indicates that significant difference was not found with either of adjacent cohorts, but these two neighbouring cohorts were significantly different among them.

\subsection{Core and skin temperature mapping in children: comparison with existing studies}

Results from the current study were compared with those found in the literature, as summarized in Table 1. Average skin temperature values at various locations are 
presented in Figure 5a, and when available in the literature, values are for female, male or asleep subjects (Figure 5b). Points connected with a solid line represent the results from the current study, while scatter points represent results from other studies.

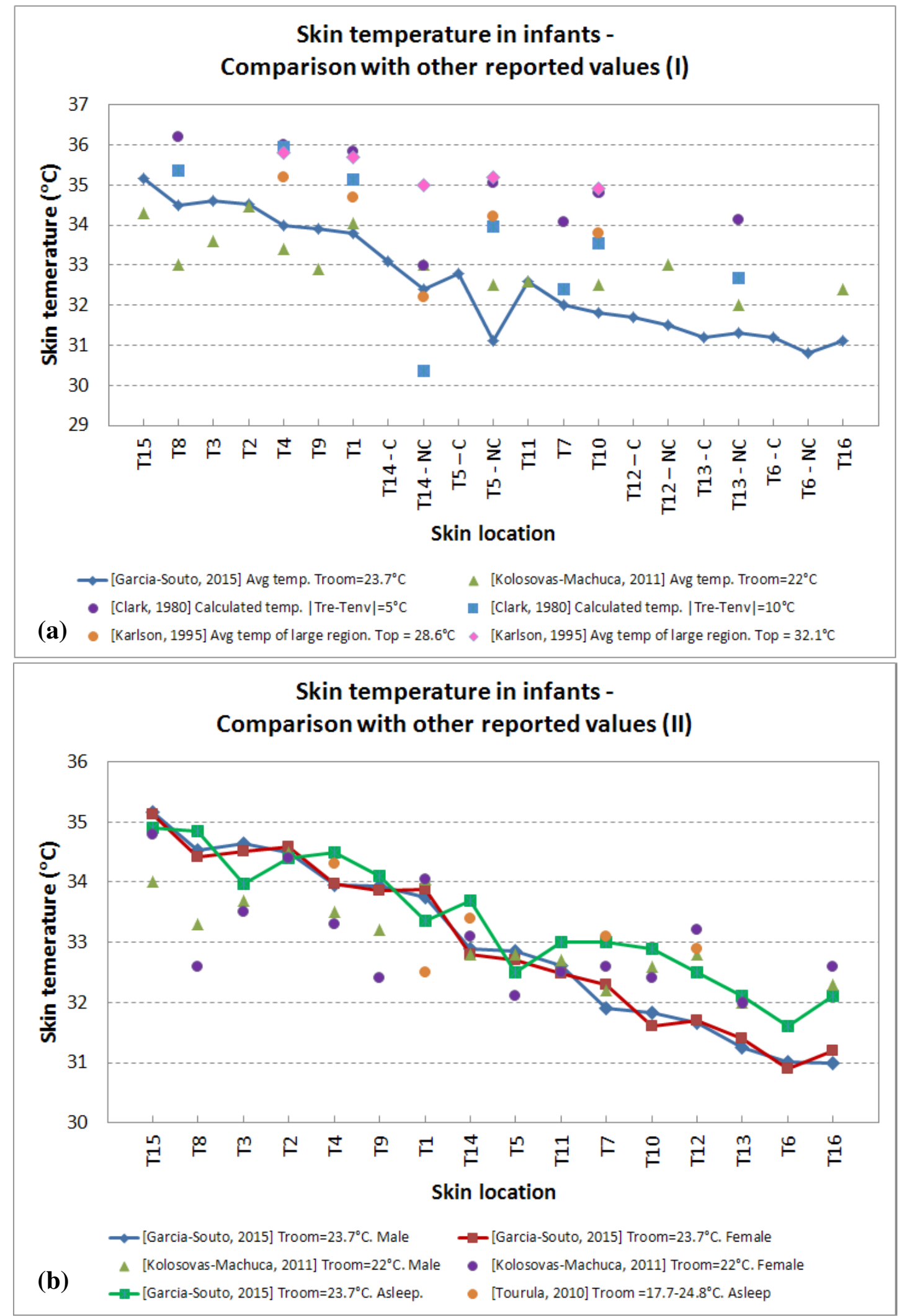

Figure 5 (a \& b): Skin temperature in infants - Comparison of current results with others existing studies in the literature detailed in Table 1. 


\section{Discussion}

\subsection{Core and skin temperature in infants}

The core temperature and local skin temperatures in infants showed mostly normal distributions. This confirms that the obtained data for core temperature are reliable, sample size is sufficient and methodology appropriate.

Core temperature in toddlers seems to be dependent on the gender and status of the infant, and use-of-blanket-while-sleeping; while age and BMI have been discarded as possible factors. A difference of $0.33 \pm 0.04{ }^{\circ} \mathrm{C}$ (higher for awake children than those asleep) was observed, which is quite significant considering the small range in which core temperature is generally kept. Activity level, quantified as the metabolic rate, is an accepted factor of the core temperature [54,55] hence supporting our results. Interestingly the core temperature is slightly higher when babies are not covered with a blanket $\left(0.17 \pm 0.08^{\circ} \mathrm{C}\right)$. Heat loss might induce a thermoregulatory response such as an increase on the metabolic rate and subsequently core temperature to protect against a possible temperature drop. Instead when sleeping with a blanket the babies' metabolic rate is lower, hence they sleep deeper. Similarly longer sleeping times were observed by Tourula et al [30] although they associate this difference to colder environmental temperatures. Finally, core temperature was found to be statistically significantly higher for female than for male babies by $0.12 \pm 0.04{ }^{\circ} \mathrm{C}$ on average. This pattern was both observed while infants were awake and sleeping, and no related to the clothing.

Local skin temperature in toddlers seems to be dependent on BMI, clothing, activity and age, while it remained mostly the same for both genders. A consistent decrease of skin temperature was detected in most locations as the BMI of the subjects increased, similarly to adults [58], with deviations from 0.5 to $0.8^{\circ} \mathrm{C}$ at upper arm, lower limbs, abdomen and back, where the increase of the BMI is more visible. This was expected as the adipose tissue acts as an insulator, protecting the temperature of the internal organs from the environment and reducing the transfer of heat to the skin. .

The level of activity of the children (characterized as awake vs. light sleep) was found to be relevant at all local skin locations, similarly to which was occurs in adults [54]. Typical exposed locations on the body like forehead and right scapula appears to 
decrease about $0.5^{\circ} \mathrm{C}$ in temperature when the baby falls asleep, highly likely due the decrease in the level of activity and heart rate, and this seems independent of the use-ofblanket. Temperature increases at all other locations $\left(0.5-1.0^{\circ} \mathrm{C}\right)$ partly due to the increase of the thermal clothing insulation provided by the use of blankets (tog of 2.5). However, a decrease of $0.5^{\circ} \mathrm{C}$ for prolong sleeping may have an adverse effect and trigger cold. Hence one needs to investigate the right level of room temperature and increase it if blankets are not used.

Clothing proved to cause a significant and positive increase on skin temperature at arms and instep (Figure 3), with the greatest increase occurring with the first layer placed over the skin. However, no significant increase was found at the lower limbs, perhaps due to the opening of the trousers which allows air circulation, reducing the thermal clothing insulation of the area. The effect of age is discussed in the next section.

\subsection{Core and skin temperature: comparison between awake infant and adult populations}

The effects of growth and maturation were investigated (Table 4-6, Figure 4). Core temperature in infants is about $0.38^{\circ} \mathrm{C}$ higher than in adults, when the literature indicates that it should be the same in thermoneutral environments [17] and at rest [15] and only greater when exposed to heat [15]. This might be partly due to the difference in activity level, as adults remained seated while children were free to move, although children's activity level was also small. However the results seem to indicate that toddlers are more sensitive to the heat strain than adults at the same normal ambient conditions, no quite as predicted in the literature [18,23], and therefore the environmental conditions need to be more properly adapted to their needs.

Local skin temperature in infants seem to generally follow similar characteristics than for adults, with a similar ranking of location based on temperature and greater SD in the temperature distributions at limbs and peripheral areas. Local skin temperature seems to increase over the childhood at forehead and upper arms, but most significantly at hands (mainly between 3-12 months of age) and shins (more steadily across 3-24 months). The observed increase of temperature (over 1 and $2^{\circ} \mathrm{C}$ for shins and hands respectively over the first 2 years of life) is close to the difference of $0.85^{\circ} \mathrm{C}$ observed by Svedberg et al. 
[56] at foot dorsal skin between non-walking and healthy children 2-7 years of age, and $2-3^{\circ} \mathrm{C}$ lower temperature observed by Huizenga et al. [27] at hands when unconstrained. We believe that this increase of temperature might be the result of muscle and blood circulation development, and the different time scales reflect the earlier development of upper limbs (handling objects for instance) than lower limbs (as for walking). Once in the adulthood, as we grow older, the skin temperature starts to decrease at abdomen, upper arm and most significantly shins, as also observed by Inoune et al. [58]. This is perhaps caused by some reduction in the activity level, and associated loss of musculature, but also partly by a possible increase of BMI with age. Temperature at hands increases significantly with age, partly because the manual activity remains. This finding has potential bearing on the way climatic controls are set for the different age groups, as the lack of muscle development and lower activity levels suggest higher temperature setting might be needed for lower age group.

BMI in both infants and adults was observed to be a significant factor $(\mathrm{p}<0.05)$ for skin temperature at locations where an increase on BMI is more noticeable, i.e. upper chest, and abdomen; and also at forehead. Temperatures at other skin locations such as upper arm, hands and shins, and the core temperature seem to remain independent of the BMI during the infancy (at least up to 2 years of age) while this changes in the adulthood. This observation might have to be taken with care as the typical BMI values in the infant sample were lower (ranging 14.4 to $21.8 \mathrm{~kg} / \mathrm{m}^{2}$ ) than those associated with the adult sample (ranging 18.5 to $31.1 \mathrm{~kg} / \mathrm{m}^{2}$ ). However it supports that slender adults have perhaps a greater ability to thermoregulate during exposure to cold [58].

The gender was observed to be significant $(\mathrm{p}<0.05)$ for core body temperature and hands temperature both in infants and adults while it does not influence skin temperature at central locations such as upper chest and abdomen, or even forehead. Clothing is a recognized factor on the skin temperature, and was corroborated by this study for the adult and the infant cohort at the upper arm and shin location.

The thermal response proved to differ in the studied age group for infants and the results show different trends. We suggest that the thermal control in nursery areas should reflect the toddlers' daily activities and age group. Specifically if performing some 
physical activity, the environmental temperature for elder toddlers could and should be brought down in order to ensure they retain lower core temperature.

\subsection{Core and skin temperature mapping in children: comparison with other studies}

The comparison of the core and skin temperature distributions observed for infants in the current work with others in the literature was challenging. There are only few studies (summarized in Table 1) that report local skin temperature information for infants, and they follow a wide variety of experimental protocols and target population.

It is difficult to establish a "normal" value for core temperature, as it changes during the day and depends on the measurement location. However the ear canal temperatures obtained in this study $\left(36.59^{\circ} \mathrm{C}\left(\mathrm{SD}=0.40^{\circ} \mathrm{C}\right)\right)$ is realistic when compared with the ranges of rectal temperature $\left(36.5-37.5^{\circ} \mathrm{C}\right)$ and axillary temperature $\left(35.6-37^{\circ} \mathrm{C}\right)$ reported for new-borns [57].

Temperatures at head and trunk of the body were greater than those at the limbs, as previously reported in the literature (Figure 5a), following a similar 'ranking'. The observed overall difference (about $4^{\circ} \mathrm{C}$ between neck and wrist in our study) is greater than those observed by Clark [32], Karlson [31] or Kolosovas-Machuca [33]. This was expected as their studies were conducted at higher room temperatures and on naked infants. Our results indicate that gender is not a differential factor for skin temperature (Figure 5b) contrary to Kolosovas-Machuca [33] observations, particularly at abdomen, paravertebral, and neck. The observed skin temperature while sleeping were encouragingly similar to those reported by Tourula [30], who followed a protocol closely resembling our study - clothed subjects and similar room temperature-.

\section{Conclusion}

The thermoregulatory responses of children have been reported to be different than those of the adults, and yet the existing comfort models only cater for the adult population. This project aimed to characterize the core body temperature and local skin temperature in infants aged 3-24 months, something that was not previously reported in the literature. We focused on clothed children while in nursery premises as it is a representation of every-day situations and it is perhaps a good example of when the 
climate control systems should be set according to the children's needs. The gender representation was balanced and the sample size was substantially large so as to make the results a more reliable reflection of the population.

The effects of age maturation were investigated by comparing the temperature mapping and their factors for the infant and adult population. For instance the core temperature in infants is higher than in adults, but the local skin temperature increases with age in toddlers at forehead and limbs (hand and shins more significantly) while it reduces in late adulthood at abdomen, upper chest and shins. An exception is the hands temperature, which increases with age even during middle-late adulthood. In general both core and skin temperature show higher dependence on BMI with maturation, but dependence with gender remains the same and only relevant for core and hands temperature.

We suggest that climatic control in the nurseries should be set to match the activity level and this could be achieved by timing the activities and setting temperature level at the relevant time windows. This strategy requires further research in terms of effective climatic control, i.e. rate of change. The other finding that we believe is highly relevant is that we have found points on the skin that maintain stable temperature and are appropriate for non-invasive indirect assessment of core temperature for temperature change alerts.

\section{Acknowledgments}

This work was partly supported by AITEX (children monitoring) and partly supported by the EC. The authors express their gratitude to the financial sponsors and the company partners Thales, AITEX and INESCOP for their support. We would also like to thank the nurseries and volunteers that took part in this study, and to the School of Engineering and Material Science, Queen Mary, University of London for their support.

\section{References}

[1] Martin CJ. Thermal adjustment of man and animals to external conditions. The Lancet 1930:617-20. Series of lectures II.

[2] Huizenga C, Hui Z, Arens E. A model of human physiology and comfort for assessing complex thermal environments. Build Environ 2001;36:691-9. 
[3] Munir A, Takada S, Matsushita T. Re-evaluation of Stolwijk's 25-node human thermal model under thermal-transient conditions: Prediction of skin temperature in low-activity conditions. Build Environ 2009;44:1777-87.

[4] Salloum M, Ghaddar A, Ghali K. A new transient bioheat model of the human body and its integration to clothing models. Int J Therm Sci 2007;46:371-84.

[5] Stolwijk JAJ, Hardy JD. Temperature regulation in man: a theoretical study. Pflügers Arch Gesamte Physiol Menschen Tiere 1966;291:129-62.

[6] Stolwijk JAJ. Mathematical model of thermoregulation. In: Charles C, editor. Physiological and Behavioral Temperature Regulation. Illinois: Thomas Publishing Company; 1970.

[7] Tanabe S, Kobayashi K, Nakano J, Ozeki Y, Konishi M. Evaluation of thermal comfort using combined multi-node thermoregulation $(65 \mathrm{MN})$ and radiation models and computational fluid dynamics. Energ Build 2002;34:637-46.

[8] Foda E, Almesri I, Awbi HB, and Sirén K. Models of human thermoregulation and the prediction of local and overall thermal sensations. Build Environ 2011;46(10):202332 .

[9] Fiala D, Havenith G, Bröde P, Kampmann B, Jendritzky G. UTCI-Fiala multi-node model of human heat transfer and temperature regulation. Int $\mathbf{J}$ Biometeorol 2012;56(3):429-41.

[10] Hensley DW, Mark AE, Abella JR, Netscher GM, Wissler EH, and Diller KR. 50 Years of Computer Simulation of the Human Thermoregulatory System. J Biomech Eng 2013;135(2):021006 1-9.

[11] Fiala D, Lomas K, and Stohrer M. A computer model of human thermoregulation for a wide range of environmental conditions: the passive system. J Appl Physiol [Online] 1999;87(5):1957-1972.

[12] Fiala D, Lomas K, and Stohrer M. Computer prediction of human thermoregulatory and temperature responses to a wide range of environmental conditions. Int $\mathrm{J}$ Biometeorol [Online] 2001;45(3):143-159.

[13] Takada S, Hokoi S, Kawakami N, and Kudo M. Thermophysiological responses of human body in non-steady state considering influence of transfer and storage of heat and moisture in and around clothing. J Architecture Plann Environ Eng 2001;549:23-30.

[14] Takada S, Kabayashi H, and Matsushita T. Thermal model of human body fitted with individual characteristics of body temperature regulation. Build Environ [Online] 2009;44(3):463-470.

[15] TsuzukiHayakawa K, Tochihara Y, Ohnaka T. Thermoregulation during heat exposure of young children compared to their mothers. Eur J Appl Physiol Occup Physiol 1995;72(1-2):12-17.

[16] Bach V, Telliez F, Krim G, Libert JP. Body temperature regulation in the newborn infant: interactions with sleep and clinical implications. Neurophysiol Clin 1996;26:379-402.

[17] Falk B. Effects of thermal stress during rest and exercise in the paediatric population. Sports Med 1998;25(4):221-240.

[18] Falk B, Dotan R. Children's thermoregulation during exercise in the heat - a revisit. Appl Physiol Nutr Metab 2008;33(2):420-427. 
[19] Fleming PJ, Azaz Y, Wigfield R. Development of thermoregulation in infancy: possible implications for SIDS. J Clin Pathol 1992;45:17-9 [as cited by Bach 1996 [16]].

[20] Guilleminault C, Leger D, Pelayo R, Gould S, Hayes B, Miles L. Development of circadian rhythmicity of temperature in full-term normal infants. Neurophysiol Clin 1996;26:21-29.

[21] Zornoza-Moreno M, Fuentes-Hernandez S, Sanchez-Solis M, Rol MA, Larque E, Madrid JA. Assessment of circadian rhythms of both skin temperatura and motor activity in infants during the first 6 months of life. Chronobiol Int 2011;28(4):330-37.

[22] Anderson GS, Mekjavic IB. Thermoregulatory responses of circum pubertal children. Eur J Appl Physiol Occup Physiol 1996;74(5):404-10.

[23] Rowland T. Thermoregulation during exercise in the heat in children: old concepts revisited. J Appl Physiol 2008;105(2):718-724.

[24] Garcia-Souto MdP, Dabnichki P. Skin temperature distribution and thermoregulatory response during prolonged seating. Build Environ 2013;69:14-21.

[25] Mehnert P, Malchaire J, Kampmann B, Piette A, Griefahn B, Gebhardt H. Prediction of the average skin temperature in warm and hot environments. Eur $\mathbf{J}$ Appl Physiol 2000;82:52-60.

[26] Werner J, Reents T. A contribution to the topography of temperature regulation in man. Eur J Appl Physiol Occup Physiol 1980;45:87-94.

[27] Webb P. Temperatures of skin, subcutaneous tissue, muscle and core in resting men in cold, comfortable and hot conditions. Eur J Appl Physiol Occup Physiol 1992;64:471-6.

[28] Huizenga C, Zhang H, Arens E, Wang D. Skin and core temperature response to partial- and whole-body heating and cooling. J Therm Biol 2004;29:549-58.

[29] Houdas Y, Ring EFJ. Human body temperature: its measurement and regulation. New York and London: Plenum Press; 1982.

[30] Tourula M, Isola A, Hassi J, Bloigu R, Rintamäki H. Infants sleeping outdoors in a northern winter climate: skin temperature and duration of sleep. Acta Paediatr 2010;99:1411-1417.

[31] Karlsson H, Hänel SE, Nilsson K, Olegård R. Measurement of skin temperature and heat flow from skin in term newborn babies. Acta Paediatr 1995;84:605-612.

[32] Clark RP, Stothers JK. Neonatal skin temperature distribution using infra-red colour thermography. J Physiol 1980;302:323-333.

[33] Kolosovas-Machuca ES, Javier González F. Distribution of skin temperature in Mexican children. Skin Res Technol 2011;17:326-331.

[34] Teli D, Jentsch MF, James PAB. Naturally ventilated classrooms: An assessment of existing comfort models for predicting the thermal sensation and preference of primary school children. Energy Build 2012;53:166-82.

[35] Teli D, James PAB, Jentsch MF. Thermal comfort in naturally ventilated primary school classrooms. Build Res Inf 2013;41(3):301-16. 
[36] Ter Mors S, Hensel JLM, Loomans MGLC, Boerstra AC. Adaptive thermal comfort in primary school classrooms: Creating and validating PMV-based comfort charts. Build Environ 2011;46:2454-2461.

[37] Xu Z, Etzel RA, Su H, Huang C, Guo Y, Tong Shilu. Impact of ambient temperatura on children's health: A systematic review. Environ Res 2012;117:120-131.

[38] De Giuli V, Da Pos O, De Carli M. Indoor environmental quality and pupil perception in Italian primary schools. Build Environ 2012;56:335-345.

[39] Zurek G, Dudek K, Pirogowicz I, Dziuba A, Pokorsk M. Influence of mechanical hippotherapy on skin temperature responses in lower limbs in children with cerebral palsy. J Physiol Pharmacol 2008;59:819-824.

[40] Saxena AK, Willital GH. Infrared thermography: Experience from a decade of pediatric imaging. Eur J Pediatr 2008;167:757-764.

[41] Vuorela N, Saha MT, Salo M. Toddlers get slimmer while adolescentes get fatter BMI distribution in five birth cohorts from four decades in Finland. Acta Paediatr 2010;100:570-577.

[42] Simpson RC, McEvoy HC, Machin G, Howell K, Naeem M, Plassmann P et al. Infield-of-view thermal image calibration system for medical thermography applications. Int J Thermophys 2008;29(3):1123-1130.

[43] Jiang L, Yao R. Modelling personal thermal sensations using C-Support Vector Classification (C-SVC) algorithm. Build Environ 2016;99: 98-106.

[44] Ning H, Wang Z, Zhang X, Ji Y. Adaptive thermal comfort in university dormitories in the severe cold area of China. Build Environ 2016;99:161-169.

[45] Kotopouleas A, Nikolopoulou M. Thermal comfort conditions in airport terminals: Indoor or transition spaces?. Build Environ 2016;99: 184-199.

[46] Lan L, Lian Z. Ten questions concerning thermal environment and sleep quality. Build Environ 2016; 99:252-259.

[47] Wang H, Hu S. Experimental study on thermal sensation of people in moderate activities. Build Environ 2016;100:127-134.

[48] International Standard Organization. ISO 9886:2004(E), Ergonomics - Evaluation of thermal strain by physiological measurements. 2004.

[49] WHO World Health Organization. Website: http://www.who.int/ [16 November 2015].

[50] WHO-BMI Children BMI information in children, given by WHO. Website: http://www.who.int/childgrowth/en/ [3 July 2015].

[51] Araźny A. Variability of the predicted insulation index of clothing in the Norwegian Arctic for the period 1971-2000. Pol Polar Res 2006;27:341-57.

[52] Houdas Y, Colin J, Timbal J, Boutelier C, Guieu JD. Skin temperatures in warm environments and the control of sweat evaporation. J Appl Physiol 1972;33:99-104.

[53] Nagano K, Takaki A, Hirakawa M, Tochihara Y. Effects of ambient temperature steps on thermal comfort requirements. Int J Biometeorol 2005;50:33-9.

[54] Webb P. Daily activity and body temperature. Eur J Appl Physiol 1993;66:174-7. 
[55] Hayward JS, Eckerson JD and Collis ML. Thermoregulatory heat production in man: prediction equation based on skin and core temperatures. J Appl Physiol 1977;42(3):377-384.

[56] Svedberg LE, Stener-Victorin E, Nordahl G, Lundeberg T. Skin temperature in the extremities of healthy and neurologically impaired children. Eur J Paediatr Neurol 2005;9(5):347-54.

[57] Freer Y, Lyon A. Temperature monitoring and control in the newborn baby. Paediatr Child Health 2012;22(4):127-130.

[58] Inoue Y, Nakao M, Araki T and Ueda H. Thermoregulatory responses of young and older men to cold exposure. Eur J Appl Physiol 1992; 65: 492-498 